\title{
SISTEM INFORMASI PENGELOLAAN UANG PEMBANGUNAN PADA JEMAAT GMIH ELIEM BALISOAN MENGGUNAKAN BORLAND DELPHI
}

\section{MONEY MANAGEMENT INFORMATION SYSTEM DEVELOPMENT AT THE CHURCH OF GMIH ELIEM BALISOAN USING BORLAND DELPHI}

\author{
Agristoria Nyong $^{1}$, Abdullah Bandang ${ }^{2}$ \\ Program Studi Komputerisasi Akuntansi \\ Program Studi Teknik Komputer \\ Politeknik Sains dan Teknologi Wiratama Maluku Utara \\ agristorianyong@gmail.com
}

\begin{abstract}
Abstrak
Jemaat GMIH Elim Balisoan adalah salah satu dari sekian banyak Gereja yang terdaftar sebagai anggota dari Persekutuan Gereja-Gereja Indonesia (PGI). Dalam hal pencatatan transaksi pembayaran uang pembangunan panitia Jemaat Elim Balisoan masih mendaptkan kesulitan yang kerap kali menimbulkan kesalahan, baik itu kesalahan pencatatan transaksi ataupun kesalahan dalam menjumlahkan uang pembangunan. Penelitian ini bertujuan untuk membuat sistem informasi pengelolaan uang pembangunan. Metode analisis dan pengembangan sistem yang digunakan adalah analisis terstruktur yang meliputi flowchart, Diagram konteks, DFD, ERD sedangkan pengembangannya menggunakan metode Waterfall. Sistem ini dirancang menggunakan bahasa pemograman Borland Delphi dan menggunakan database Microsoft Acess. Dengan adanya sistem ini, diharapkan mampu menjawab kebutuhan panitia pembanguan dalam melakukan proses pengelolaan uang pembangunan yang meliputi transaksi pembayaran dan pengeluaran, serta bisa meminimalisir kesalahankesalahan pencatatan transaksi keuangan pada Jemaat GMIH Elim Balisoan.
\end{abstract}

\section{Kata kunci: Sistem Informasi, Uang Pembangunan, Borland Delphi}

\begin{abstract}
Elim Church of GMIH Balisoan is one of the many Churches that are registered as a member of the Fellowship of churches of Indonesia (PGI). In the case of recording transaction payment money development committee Elim Balisoan congeretion still difficulty that often leads to errors, whether it is a mistake recording transaction or errors in summing development money. This study aims to make information system of management development. Method of analysis and system of money management development. Method of analysis and system development used is a structured analysis which includes flowchart, context diagram, DFD, ERD, while its development use waterfall method. This system is designed using Borland Delphi programming language and using the Microsoft Access database. With this system, it is expected to be able to answer the needs of the development committee in carrying out the process of managing the development money which includes payment and expense transaction and can minimize the mistakes of recording transaction finance at the Congregation of Elim GMIH Balisoan
\end{abstract}

Keywords: Information Systems, Money Management, Borland Delphi 


\section{PENDAHULUAN}

Pengolahan data transaksi sangatlah penting dalam sebuah lembaga, perusahaan atau organisasi. Jika pengolahan data tidak dikelola dengan baik maka akan menimbulkan terjadinya kesalahan data yang dapat menyebabkan terjadinya masalah. Untuk itu pengolahan data merupakan kunci utama untuk mencapai kesempurnaan. Dengan pengolahan data yang baik maka dapat menghasilkan informasi yang akurat dan jelas. Untuk mencapai hal tersebut, tentulah harus mempunyai instrumen penunjang dalam hal ini ialah bahasa pemograman yang bertujuan untuk membuat suatu aplikasi. Ada banyak bahasa pemoraman yang dikenal, salah satunya adalah Borland Delphi

Borland Delphi adalah suatu bahasa pemograman yang bekerja dalam lingkup Sistem Operasi Windows yang merupakan pengembangan bahasa pascal yang bersifat visuall. Borland delphi dapat memanfaatkan kemampuan windows secara optimal. Borland Delphi mampu membuat suatu aplikasi berbasis windows yang mudah untuk dioperasikan atau dijalankan, dan sangat cocok apabila diterapkan pada lembaga atau perusahaan yang membutuhkan aplikasi yang bisa mencatat transaksi pembayaran dan pengeluaran. Akan tetapi masi banyak lembaga atau perusahaan yang belum memanfaatkan kemajuan teknologi sebagai suatu sarana dalam meningkatkan keefisisensi lembaga, perusahaan atau tempat pelayanan seperti pada tempat ibadah. Salah satunya adalah tempat ibadah yang mengelola data jemaat adalah Gereja GMIH Elim Balisoan.

Jemaat GMIH Elim Balisoan adalah suatu Organisasi Gereja yang aktif dan terdaftar dalam Persekutuan Gereja Gereja
Indonesia (PGI) yang bertempat di Desa Balisoan Kec. Sahu Kab. Halmahera Barat. Dalam pengolahan transaksi pembayaran dan pengeluaran uang pembangunan yang dilakukan pada Jemaat Elim, mekanismenya masih dilakukan dengan cara konvesional atau manual misalnya setiap transaksi dicatat menggunakan tulis tangan yang kerap kali memicu terjadinya kesalahan dan berpengaruh pada pembuatan laporan keuangan yang tidak akurat dan maksimal. Selain itu, pengolahan transaksi pembayaran dan pengeluaran yang masih dilakukan dengan media seperti kalkulator yang harus menjumlahkan transaksi pembayaran secara satu persatu cara ini dapat menyita waktu sehingga dianggap kurang efektif dan perlu diusulkan suatu sistem yang terkomputerisasi agar dapat membantu dalam mendukung kinerja dan pelayanan pada gereja GMIH Elim Balisoan.

\section{Rumusan Masalah}

Bagaimana merancang sistem informasi pengelolaan uang pembangunan pada Jemaat GMIH Elim Balisoan dalam menyajikan laporan transaksi keuangan yang ideal kepada jemaat dan pimpinan jemaat, dan meningkatkan efisiensi serta efektifitas panitia dalam melakukan pekerjaan di GMIH Elim Balisoan.

\section{LANDASAN TEORI Pengertian Sistem}

Sistem adalah sekolompok elemenelemen yang terintegrasi dengan tujuan yang sama untuk mencapai tujuan. Sistem juga merupakan suatu jaringan kerja dari prosedur-prosedur yang saling berhubungan, terkumpul bersama-sama untuk melakukan suatu kegiatan atau tujuan tertentu (Yakub, 2012:1) 


\section{Pengertian Informasi}

Informasi adalah data yang telah diolah menjadi sebuah bentuk yang berguna dan nyata atau berupa nilai yang dapat dipahami dalam keputusan sekarang maupun yang akan datang (Al Bahra Bin Ladjamudin, 2013: 8)

\section{Uang Pembangunan}

Uang adalah suatu benda dengan satuan hitung yang dapat digunakan sabagai alat pembayaran yang sah dalam berbagai transaksi dan berlaku didalam wilayah tertentu. Demikian fungsi uang sehingga keberadaan uang di suatu Negara diatur dengan undang-undang (KBBI 2017).

Pada hakekatnya pengertian pembanguunan secara umum adalah suatu proses perubahan yang terus menerus untuk menuju keadaan yang lebih baik berdasarkan norma-norma tertentu (KBBI 2017).

\section{Anggota Sidi}

Anggota sidi adalah anggota jemaat yang sudah masuk usia dewasa dan yang telah bersedia untuk di teguhkan sidinya, dan juga suah memiliki tanggung jawab pribadi kepada Gereja maupun jemaat (Pdt, Hofni Parmino S,Th 'Pimpinan Jemaat GMIH Elim Balisoan').

\section{Pengelolaan Keuangan}

Pengelolaan artinya penggunaan sumber daya secara efektif dan efisien. Pengelolaan keuangan adaalah sumber daya yang diterima yang akan dipergunkan untuk penyelenggara. Pengelolaan keuangan dimaksud sebagai suatu pengelolaan terhadap fungsi-fungsi keuangan

\section{Pengembangan Sistem}

Muharto dan Ambarita (2016:106), "Pengembangan sistem merupakan aktivitas untuk menghasilkan sistem informasi berbasis komputer untuk menyelesaikan persoalan (problem) organisasi atau memanfaatkan kesempatan (opportunities) yang timbul. Menyusun suatu sistem yang baru untuk menggantikan sistem yang lama secara keseluruhan atau memperbaiki sistem yang ada".

\section{Alat Bantu Pengembangan Sistem Flowchart}

Alfitri (2011:16), Flowchart adalah simbol - simbol pekerjaan yang menunjukkan bagan aliran proses yang saling terhubung. Jadi, setiap simbol flowchart melambangkan pekerjaan dan instruksinya. Simbol-simbol flowchart adalah standar yang ditentukan oleh Amerika National Standard Institute Inc.

Menurut Krismiaji (2011:71) Flowchart merupakan teknik analitis yang digunakan untuk menjelaskan aspek-aspek sistem informasi secara jelas, tepat dan logis. Bagan alir menggunakan serangkaian simbol standar untuk menguraikan prosedur pengolahan transaksi yang digunakan oleh sebuah perusahaan, sekaligus menguraikan aliran data dalam sebuah sistem

\section{Data Flow Diagram (DFD)}

Definisi menurut Tata Sutabri (2012:117), Data Flow Diagram adalah sebagai suatu network yang menggambarkan suatu sistem automat/komputersasi, manualisasi, atau gabungan dari keduanya, yang penggambarannya disusun dalam bentuk kumpulan komponen sistem yang saling berhubungan sesuai dengan aturan mainnya. 
Menurut Yakub (2012:155) Data Flow Diagram (DFD) merupakan alat untuk membuat diagram yang serbaguna.

\section{Entity Relationship Diagram (ERD)}

Menurut Sutanta (2011:91) "Entity Relationship Diagram (ERD) merupakan suatu model data yang dikembangkan berdasarkan objek.

Entity Relationship Diagram (ERD) merupakan salah satu alat bantu (berupa gambar) dalam model database relasional yang berguna untuk menjelaskan hubungan atau relasi antar tabel yang terdapat didalam database. ( Budi Raharjo, 2011:57).

\section{Pengertian Data Base}

Basis data atau database dapat didefinisikan sebagai himpunan kelompok data yang saling berhubungan yang diorganisasikan sedemikian rupa agar kelak dapat dimanfaatkan kembali dengan cepat dan mudah. (Priyanto dan Jahuari, 2015:147)

Menurut Kustiyaningsih, (2011:146) Database adalah struktur penyimpanan data. Untuk menambah, mengakses dan memproses data yang disimpan dalam sebuah database komputer, diperlukan system manajemen database seperti $M y S Q L$ Server

\section{Pengujian Sistem Blackbox}

Menurut Simarmata (2011:323), adalah pengujian yang dilakukan hanya mengamati hasil eksekusi melalui data uji dan memeriksa fungsional dari perangkat lunak. Pengujian black box mengevaluasi anya dari tampilan luarnya saja (interface), fungsionalitasnya tanpa engetahui sesungguhnya yang terjadi dalam proses detilnya (hanya mengetahui input dan output).

\section{Pengertian Borland Delphi}

Menurut Kusnassriyanto (2011:1) pada awalnya dephi adalah proyek rahasia di Borland yang berevolusi menjadi sebuah produk yang disebut appbuilder. Sesaat sebelum rilis pertama dari borland, novell appbuilder dirilis sehingga borland harus memberikan nama baru untuk proyek tersebut. Salah satu tujuan asli dari Delphi pada waktu itu adalah untuk menyediakan konektivitas database untuk programmer sebagi fitur kunci dan database yang paling popular pada waktu itu adlah oracle

\section{METODE PENELITIAN}

Pengumpulan data dilakukan untuk memperoleh informasi yang dibutuhkan dalam rangka mencapai tujuan penelitian. Pengumpulan data dalam penelitian ini menggunakan teknik wawancara. Wawancara adalah teknik pengumpulan data yang dilakukan melalui tatap muka dan tanya jawab langsung anatara peneliti dan narasumber. Dan wawancara tersebut dilakukan kepada pimpinan jemaat Gmih Elim Balisoan, dan juga bendahara pembangunan Jemaat GMIH Balisoan. Jenis data yang digunakan adalah data primer.

\section{Metode Pengembangan Sistem}

Metode yang digunkan dalam tahap pengembangan sistem adalah metode waterfall, dimana pendekatan dilakuan secara sistematis dimulai dari kebutuhan sistem yang meliputi sejarah organisasi Gereja GMIH Elim Balisoan, struktur organisasi, dan juga pembagian tugas tanggung jawab, kemudian tahap yang berikut adalah tahap desain sistem, dimana dalam penelitian ini tahap tersebut digambarkan pada sistem yang berjalan 
dan diusulkan menggunakan digram flowchart, DFD, ERD, Tabel relasi, tampilan layout, setelah itu masuk pada tahap codingan, tahap ini merupakan tahap pembuatan sistem atau aplikasi dengan menggunakan bahasa pemograman Borland Delphi. Setelah tahap codingan selesai maka sistem di implementasikan dan diuji dengan menggunakan metode black box atau white box, dan tahap akhir adalah tahap maintenance atau tahap pemeliharaan

\section{Kebutuhan Fungsional dan Non- Fungsional}

Kebutuhan fungsional didalamnya berisi proses-proses apa saja yang nantinya dilakukan oleh sistem, sedangkan kebutuhan nonfungsional merupakan kebutuhan yang berisi tentang isntrumen pendukung yang digunakan oleh sistem itu sendiri. Pada sistem informasi pembayaran dan pengeluaran uang pembangunan pada jemaat GMIH Elim Balisoan kebutuhan fungsionalnnya meliputi:

\section{Pendataan Angota}

1. Pengguna memasukan data data aggota sidi seperti, nama, alamat, nomor telepon (jika ada)

2. Pengguna dapat mencetak daftar nama anggota secara keseluruhan.

\section{Transaksi Pembayaran:}

1. Sistem mampu menampilkan secara rinci laporan setoran anggota sidi, yang meliputi tanggal pembayaran, jumlah pembayaran, dan keterangan.

2. Sistem mampu menghitung jumlah setoran yang telah dibayar oleh anggota sidi ataupun yang belum dibayar oleh anggota sidi.

\section{Transaksi Pengeluaran}

Sistem mampu menampilkan rincian pengeluaran kas berupa tanggal pengeluaran, uraian pengeluaran, dan juga jumlah pengeluaran..

\section{Laporan}

Sistem mampu menampilkan laporan jurnal umum yang didalamnya ditampilkan secara keseluruhan informasi transaksi penerimaan dan juga pengeluaran.

Sistem mampu menampilkan laporan kas yang didalamnya ditampilkan secara rinci soal pendapatan dan juga biayabiaya yang dikeluarkan.

\section{Kebutuhan Non-Fungsional:}

1. Menggunakan windows 7 profesional.

2. Membutuhkan cannon ip2770.

3. Menggunakan database microsoft acces 2007 yang dilengkapi dengan password.

4. Menggunakan Microsoft Visio 2007 untuk Desain sistem

5. Bahasa Pemrograman Borland Dephi

\section{Kerangka Penilitian}

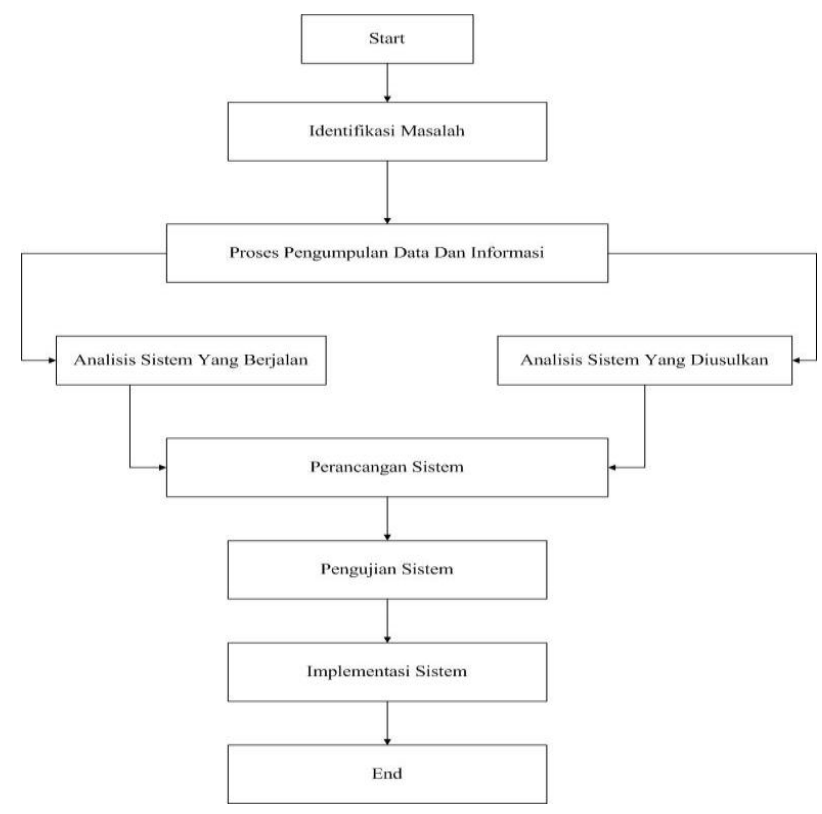

Gambar 1. Kerangka Penilitian

Analisa Sistem yang Berjalan

Analisa sistem yang berjalan

Volume 3 Nomor 1 | April 2018 
merupakan tahapan dalam melakukan indentifikasi masalah awal pada sistem yang masih konvensional dan diuraikan pada diagram flowchart sistem yang berjalan

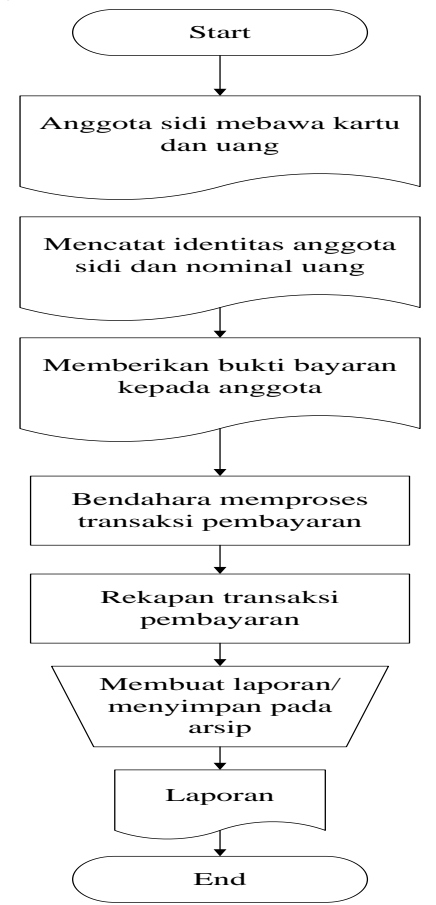

Gambar 2. Sistem yang berjalan

\section{Rancangan System yang Diusulkan}

Berdasarkan sistem yang berjalan maka peneliti mengusulkan sistem yang baru. Berikut desain flowchart sistem yang diusulkan.

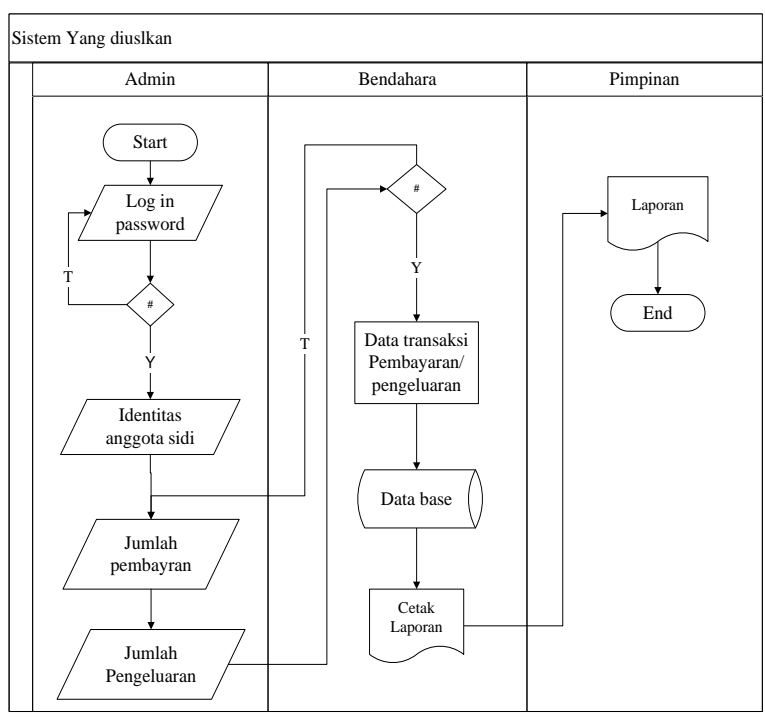

Gambar 3. Flowchart Sistem Yang

Diusulkan

\section{PERANCANGAN SISTEM \\ Perancangan Tabel Database}

Tabel 1. Tbl_iuran

\begin{tabular}{|l|l|l|}
\hline \multicolumn{1}{|c|}{ Field Name } & \multicolumn{2}{c|}{ Data Type } \\
\hline Wid & AutoNumber & Identitas luran Anggota \\
\hline Tahun & Text & Tahun (4) \\
\hline Jumlah & Currency & Besaran Jumlah luran Anggota \\
\hline
\end{tabular}

Tabel 2. Tbl_anggota

\begin{tabular}{|l|l|l|}
\hline \multicolumn{1}{|c|}{ Field Name } & \multicolumn{2}{c|}{ Data Type } \\
\hline Aid & AutoNumber & Identita Anggota \\
\hline Nama & Text & Nama Anggota (30) \\
\hline Alamat & Text & Alamat (40) \\
\hline Telp & Text & No Telp/Hp (12) \\
\hline
\end{tabular}

Tabel 3. Tbl_setoran

\begin{tabular}{|l|l|l|}
\hline \multicolumn{1}{|c|}{ Field Name } & \multicolumn{1}{c|}{ Data Type } & \\
\hline ID & AutoNumber & identitas penerimaan \\
\hline Uid & Number & identitas kas \\
\hline Wid & Number & Identitas luran Anggota \\
\hline Aid & Number & identitas Anggota \\
\hline Tgl & Date/Time & Tanggal Penerimaan Setoran \\
\hline Jumlah & Currency & Jumlah Setoran \\
\hline Ket & Number & Keterangan \\
\hline
\end{tabular}

Tabel 4. Tbl_pengeluaran

\begin{tabular}{|l|l|l|}
\hline \multicolumn{1}{|c|}{ Field Name } & \multicolumn{1}{c|}{ Data Type } \\
\hline Kid & AutoNumber & Identitas Kredit \\
\hline Uid & Number & Identitas Kas \\
\hline Pid & Number & Identitas Pengeluaran \\
\hline TgI & Date/Time & Tanggal Pengeluaran Kas \\
\hline Uraian & Text & Uraian Pengeluaran Kas (150) \\
\hline Jumlah & Currency & Jumlah Pengeluaran \\
\hline & & \\
\hline
\end{tabular}

Tabel 5. Tbl_logon

\begin{tabular}{|l|l|l|}
\hline \multicolumn{1}{|c|}{ Field Name } & \multicolumn{2}{c|}{ Data Type } \\
\hline User & Text & Nama User (15) \\
\hline Passwd & Text & Password (10) \\
\hline Level & Text & Hak Akses (10) \\
\hline
\end{tabular}

\section{IMPLEMENTASI SISTEM}


Implementasi sistem merupakan tahapan meletakan sistem yang sudah dibuat ke dalam bahasa pemrograman dan nantinya sistem tersebut akan diuji

\section{Menu Utama}

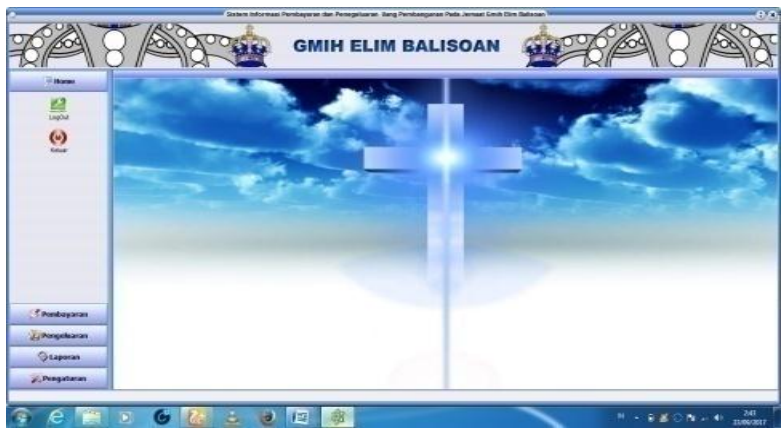

Gambar 4. Tampilan Menu utama

Halaman Menu Logon

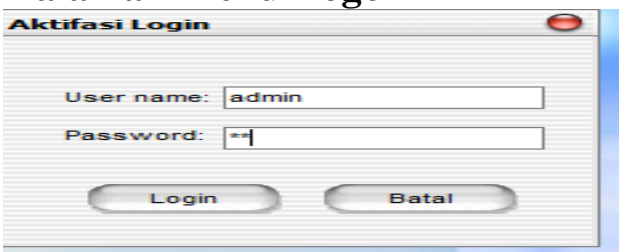

Gambar 5. Menu Logon

\section{Halaman Menu Data Anggota}

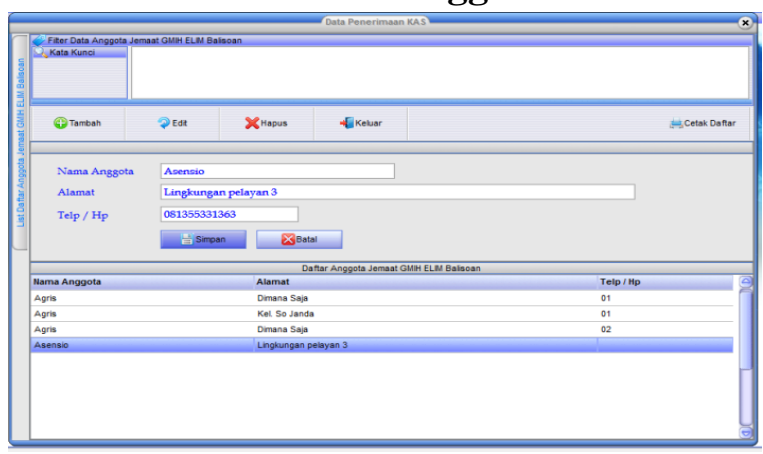

Gambar 6. Menu Data Anggota

\section{Halaman Menu Iuran Anggota}

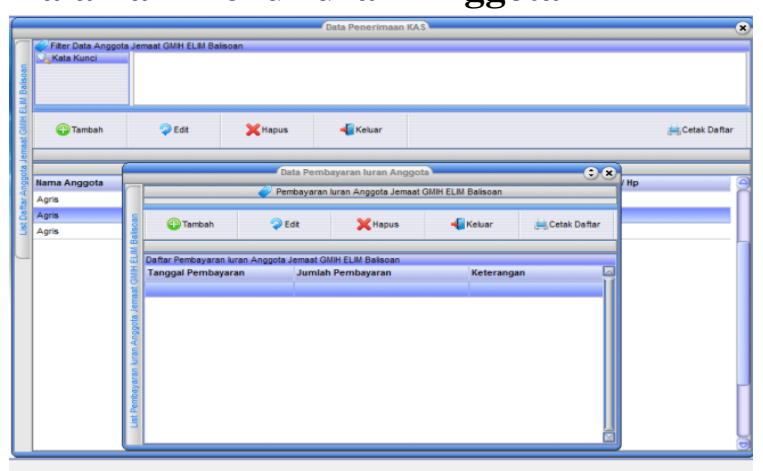

Gambar 7. Menu iuran anggota

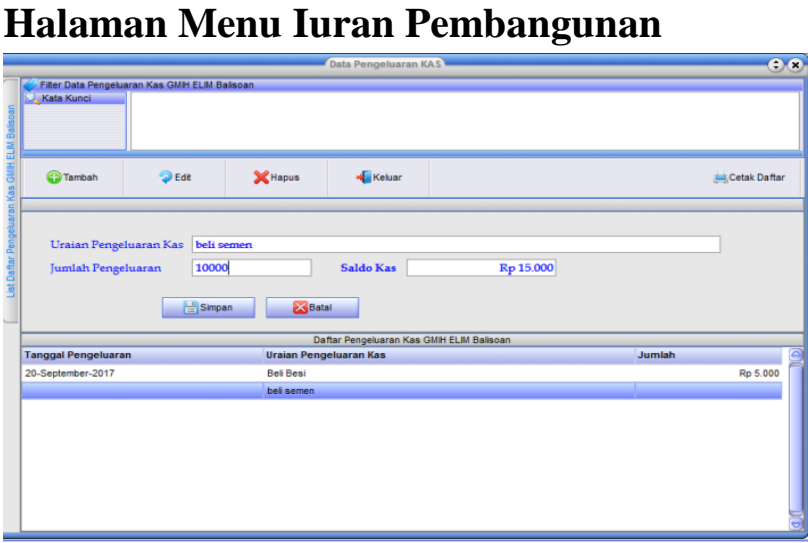

Gambar 8. Menu iuran pembanguna

\section{Halaman Menu Laporan Jurnal umum}

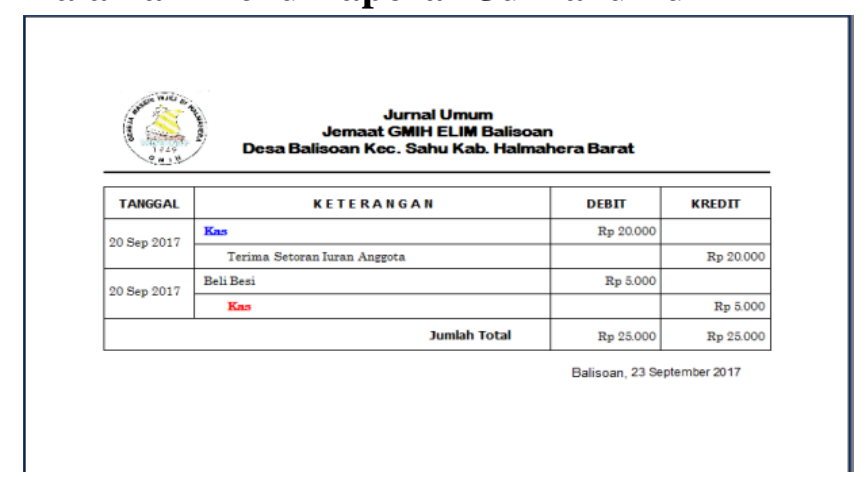

Gambar 9. Menu Laporan Jurnal Umum

Halaman Menu Laporan Kas

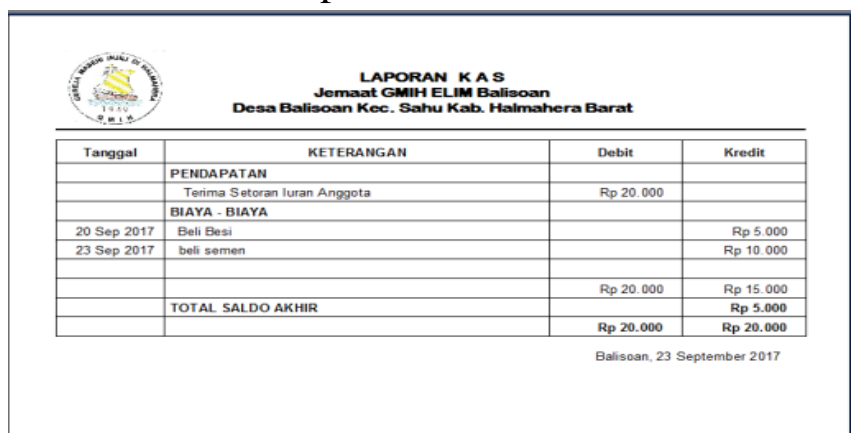

Gambar 10. Menu Laporan Kas

\section{Pengujian Sistem Blackbox}

Pengujian blackbox merupakan pengujian sistem yang menguji dasar fungsi menu yang aktif atau eror pada sistem yang sudah dibuat, berikut uraian pengujian menu sistem blacbox sebagai berikut:

Tabel 8. Pengujian Menu Utama

\begin{tabular}{|c|c|}
\hline Nama Proses & Menu utama \\
\hline & Skenario \\
\hline
\end{tabular}

Volume 3 Nomor 1 | April 2018 
pengguna diminta untuk memeilih menu-menu yang tersedia pada aplikasi yaitu, home, pembayaran, pengeluaran, laporan, dan juga pengaturan.

\section{Hasil Yang Diharapkan}

Aplikasi akan menampilkan sub-sub menu dan menampilkan interface yang dipilih, tetapi sebelum itu pengguna harus melakukan login terlebih dahulu.

Tabel 9. Pengujian Logon

\begin{tabular}{|l|}
\hline \multicolumn{1}{|c|}{ Nama Proses } \\
\hline \multicolumn{1}{|c|}{ Skenario } \\
\hline $\begin{array}{l}\text { Apabila admin memasukan username dan passwor } \\
\text { yang salah. }\end{array}$ \\
\hline \multicolumn{1}{|c|}{ Hasil Yang Diharapkan } \\
\hline $\begin{array}{l}\text { Sistem akan menolak untuk masuk ke setiap sub- } \\
\text { sub menu yang dipilih. Dan pengguna diminta } \\
\text { untuk melakukan login kembali }\end{array}$ \\
\hline
\end{tabular}

Tabel 10. Pengujian menu anggota

\begin{tabular}{|c|c|}
\hline Nama Proses & Data anggota \\
\hline & Skenario \\
\hline
\end{tabular}

1. Untuk menambahkan data anggota maka admin harus menekan tombol tambah, maka akan tersedia form untuk mengisi data anggota. Jika ingin mengedit data anggota, maka admin harus memilih nama anggota yang akan diedit, kemudian menekan tombol edit. Untuk menghapus data anggota, maka admin harus memilih nama anggota yang mau dihapus kemudian menekan tombol hapus.

2. Untuk membatalkan proses penambahan anggota, pengeditan anggota, dan pengahapusan anggota, maka admin cukup menekan tombol keluar.

3. Untuk mencetak daftar anggota maka harus menekan tombol cetak daftar.

4. Untuk mencari nama anggota berdasarkan kategori abjad, maka admin menekan mengisi nama yang ingin dicari pada kolom kata kunci

\section{Hasil Yang Diharapkan}

1. Data yang dinput dapat tersimpan kedalam daftar nama-nama anggota. Dan data anggota yang telah diedit dapat tersimpan kembali itemitem perubahan kedalam daftar nama anggota. Kemudian data yang dihapus akan dihilangkan dari daftar nama-nama anggota.

2. Sistem akan menutup jendela informasi soal data anggota.

3. Sistem akan menampilkan daftar nama anggota, alamat, dan nomor telepon yang siap diprint out.

4. Sistem akan menampilkan nama yang ingin dicari berdasarkan dengan kata kunci yang telah ditulis

Tabel 10. Pengujian Menu Iuran

\begin{tabular}{|c|c|}
\hline Nama Proses & $\begin{array}{c}\text { Pembayaran Iuran } \\
\text { Anggota }\end{array}$ \\
\hline
\end{tabular}

Skenario

1. Untuk melihat pembayaran iuran anggota, maka pengguna harus menekan tombol klik kanan.

2. Untuk mencatat setoran yang diberikan oleh anggota sidi, maka admin harus menekan tombol tambah. Jika ingin mengedit pembayaran iuran anggota yang mungkin mengalami kesalahan, maka admin menekan tombol edit, begitu juga apabila admin ingin menghapus data anggota.

3. Jika admin ingin mencetak daftar nama nama anggota yang telah menyetor uang pembangunan, maka admin menekan tombol cetak daftar.

\section{Hasil Yang Diharapkan}

1. Sistem secara otomatis akan membuka form pengisihan pembayaran iuran anggota.

2. Sistem dapat menyimpan setoran anggota yang baru ditambah kedalam database, sistem dapat menyimpan data yang telah diedit oleh admin, dan sistem dapat menghapus data setoran anggota yang dipilih oleh admin.

3. Sistem akan menampilkan secara terperinci laporan setoran anggota sidi, berapa sisa setoran anggota sidi yang belum lunas, beserta dengan keterangan lengkap yang telah melunasi dan belum melunasi.

Tabel 12. Pengujian menu pengeluaran

\begin{tabular}{|l|l|}
\hline Nama Proses & \multicolumn{1}{c|}{$\begin{array}{c}\text { Pengeluaran Uang } \\
\text { Pembangunan }\end{array}$} \\
\hline Skenario \\
\hline 1. & Jika admin mencatat transaksi pengeluaran yang \\
terjadi maka menekan tombol tambah. Untuk \\
merubah pengeluaran yang menurut admin telah \\
terjadi kesalahan maka admin menekan tombol \\
edit. Dan apabila admin ingin menghapus data \\
pengeluaran maka menekan tombol hapus.
\end{tabular}

2. Jika admin ingin mencetak laporan pengeluaran, maka menekan tombol cetak daftar.

3. Untuk mempermudah mencari jenis pengeluaran, maka admin memasukan jenis pengeluaran berdasarkan abjad pada kolom kata kunci.

1. Sistem akan menampilkan kolom untuk mengisi uraian pengeluaran, jumlah pengeluaran, dan sisa saldo terbawa. Sistem secara otomatis akan menyimpan data yang telah ditambahkan, atau diedit, dan sistem akan menghapus data yang telah dipilih untuk dihapus.

2. Sistem akan menampilkan data pengeluaran uang pembangunan yang dappat dijadikan sebagai laporan.

3. Sistem akan mennampilkan informasi terkait dengan data yang akan dicari berdasarkan kata kunci. 


\section{KESIMPULAN}

Setelah melakukan implementasi dan pengujian sistem informasi pengelolaan uang pembangunan pada jemaat GMIH Elim Balisoan, dapat diambil kesimpulan sebagai berikut: 1). Sistem ini dapat meningkatkan kinerja dan pelayanan pada admin GMIH Elim Balisoan terutama pada admin dalam mengelola data transaksi pembayaran dan pengeluaran uang jemaat. 2). Proses menghitung data transaksi dalam pembuatan laporan pada sistem dapat dilakukan secara otomatis dengan efisien

Berdasarkan kesimpulan maka disarankan untuk penelitian mendatang agar lebih mencapai kesempurnaan dari penelitian ini sebagai berikut: 1). Pada sistem tersebut belum adanya rekapan laporan Transaksi perbulan dan Pertahun dari setiap pembayaran anggota sidi. 2). Diperlukan pelatihan khusus kepada admin dalam mengunakan sistem agar dapat sistem tersebut dapat berjalan dengan optimal

\section{DAFTAR PUSTAKA}

Sutabri, Tata, (2004). Analisa Sistem Informasi. Edisi Pertama. Yogyakarta: Andi.

Jogiyanto. (2005). Analisis dan Desain

Sistem Informasi. Yogyakarta:

Penerbit Andi.

Al-Bahra Bin Ladjamudin (2005:39) Analisis dan Desain Sistem Informasi. Yogyakarta: Graha Ilmu

Wahana komputer, (2007), Menjadi seorang programer, Andi Offset, Yogyakarta

Kusrini dkk (2007:79) Tuntunan Praktis Membangun Sistem Informasi Akuntansi dengan Visual Basic dan Microsoft SQL Server
Andri Kristanto. (2008). Perancangan Sistem Informasi dan Aplikasinya, Gava Media, Yogyakarta.

Krismiaji, (2010). Sistem Informasi Akuntansi, UMP YKPN, Yogyakarta.

Mohamad Subhan (2012:109) Analisa Perancangan Sistem

Yakub (2012:1) Pengantar Sistem Informasi Yogyakarta: Graha Ilmu

Mohamad Subhan (2012:17) Analisa Perancangan Sistem

Rudy Tantra (2012:2) Manajemen Proyek Sistem Informasi

Kamus besar bahasa Indonesia online (KBBI online) Pdt, Hofni Parmino, S.Th.

Muharto \& Ambarita, A. 2016. Metode Penelitian Sistem Informasi:

Mengatasi Kesulitan Mahasiswa Dalam Menyusun Proposal Penelitian. Deepublish. Yogyakarta Adetria Halim, Syahril Hasan, Sistem Informasi Pengelolaan Uang Komite Menggunakan Borland Delphi 7 Pada SMA Negeri 5 Kota Ternate, IJIS-Indonesian Journal On Information System, Volume 2 Nomor 1 April 2017, ISSN 25486438

Arisandy Ambarita, Sistem Informasi Geografis Potensi Tanaman Pangan (Studi Kasus: Kabupaten Halmahera Barat Provinsi Maluku Utara), Indonesian Journal on Networking and Security - Volume 6 No 2 2017, ISSN: 2302-5700 (Print) 2354-6654 (Online) 